THURSDAY, SEPTEMBER 30, I 886

\section{OUR GUNS}

W HEN a careful engineer sets about designing a structure, he first determines the strain which the several parts of it will have to withstand; he then selects his material and proportions it so that it will be able to carry the strains safely ; in determining the margin which should be allowed he uses judgment based upon his own experience or that of others who have designed similar structures; and if the strains be difficult to determine, or if they be of the nature of severe and sudden shocks and complicated cross strains he increases his margin in proportion. Experience has shown, for example, that wrought iron in the form of a railway bridge may be worked safely at a load equal to one-fourth of that which will break it down, a cast-iron bridge to onesixth. The builder of a steam-engine rarely loads those parts of his machinery which have to endure sudden and reverse strains to more than one-eighth or one-tenth of their ultimate strength. If his structure fail, the first thing the engineer does is to re-calculate his strains and the dimensions he has given to the various parts, and if these should prove correct he seeks for the cause of failure in unlooked-for defects in his material; and if failure in the same class of structure, of various sizes, recur repeatedly in the same place, he comes to the conclusion, either that he has under-estimated the strains, or that the margin of safety which he has allowed is not sufficient. An engineer accustomed to act in this manner must look with dismay upon the report of the Committee appointed to examine into the cause of the failure of the I2-inch gun of the Collingrwood, and of other guns of similar construction. It is possible, of course, that the Committee have been able to calculate the strains which tend to destroy the guns, and have satisfied themselves that sufficient metal has been provided for the purpose ; but, if so, it is much to be regretted that they have not seen fit to make the results of their investigations public, because it would have been instructive to know how the stresses are arrived at and what margin of safety is considered sufficient for a gun. When Colonel Maitland read his paper on our new guns at the United Service Institution in the middle of 1884 , the strains certainly were not known to the Ordnance Committee, because the pressure curves, purporting to represent one-fourth of the bursting pressure of the guns, and which were given on the official drawings, were incompetent to account even for the muzzle energy which the shot was supposed to possess, and consequently provided nothing whatever for other important work which has to be performed during the discharge. This fact was pointed out by the Engineer early in 1885 , in an article commenting on one of the Howard Lectures which had just been delivered at the Society of Arts, and the weak point in our guns was actually indicated before any failures had taken place!

How much has the knowledge of the Ordnance Committee advanced in the meantime, and is four still considered a sufficient factor of safety? Any careful engineer who reflects on the strains a gun is subjected to would certainly class it among steam-engines, subject to the VoL. XXXIV.-No. 883 roughest work, and not to the class of railway bridges, which have well-defined and simple strains to stand. What takes place when a gun is discharged? First, there is the direct pressure of the gases, which is still very imperfectly known. Next, this pressure travels along the bore at a very rapid rate, producing a shearing strain between the material in advance of, and in rear of the base of the shot, and this strain is intensified at each point where a sudden change of thickness takes place. Thirdly, there is the reaction to the force producing rotation of the shot, which tends to twist the barrel. Fourthly, there are the strains produced by the momentary presence of a white-hot body pressing against the walls of the bore with a pressure ranging from 25 tons to $\mathrm{I}$ ton per siguare inch; and, lastly, there is the longitudinal strain representing the reaction between the pressure on the base of the bore and the inertia of the gun itself. What engineer would dream of counteracting such strains as these with a less margin than eight or ten, if he were perfectly unfettered, and if he were certain of the manner in which the strains were transmitted through the metal of the gun ; but even on this point there are grave doubts, for it seems almost certain that the strains travel as pulses or vibrations, in a manner which sets at defiance all ordinary modes of calculation. No engineer would be surprised if guns, with a factor of safety of only four, burst frequently.

But it will, no doubt, be argued that guns of the strength suggested would be impracticable. We do not hold that opinion, because weight in a gun, even for naval purposes, is not objectionable, since the force of recoil diminishes with the increase of weight, and the metal appropriated to the gun would be saved in the carriage and structure of the ship; while, for land service, weight can be no objection whatever. The Committee make no allusion to a necessity of keeping down the weight of guns, hence it must be supposed that they would not sacrifice safety to this end, although it is well known that there is a kind of race among gun-makers to produce the greatest amount of shot-energy per ton of gun. It seems to us, therefore, most unfair that the whole blame of our failures is to rest on the Royal Gun Factory, that is, on the quality of material and on the manufacture, when it is certain that the faults are faults of design-a want of sufficient metal -a view which the Committee adopt by their acts, though not by their words; for they are adding largely to the weight of the guns in the very parts which experience and the investigations of outsiders have proved to be deficient in strength.

But although the Ordnance Committee are reticent as to the scientific views which they hold respecting the structure of guns, they have a way of taking the public into their confidence, through the instrumentality of a lecture delivered by one of their body, whose talents as an agreeable expounder of popular science are well known, and they show much wisdom in making these manifestations take the form of lectures instead of papers read before scientific Societies. The advantage of a lecture is that no awkward questions can be asked, and no fallacies or errors pointed out. Thus, when the Thunderer's gun burst, Sir Frederick Bramwell delivered a very pleasant lecture at the Royal Institution, and the other day the same gentleman selected the subject of our guns as the 
theme of his address to the Midland Institute at Birmingham, and, we have no doubt, charmed his audience with his manner and ready wit. But what is there in either of the lectures just mentioned that throws the slightest light on the real difficulties of the subject? Why was not Sir F. Bramwell moved to read a paper at the meeting of the British Association which took place a few weeks ago in the very building in which he addressed the Midland Institute? Had such a paper been read, a most interesting and animated discussion would have arisen, and the nation would have had the advantage of learning the opinions of men who have devoted their lives to working out the problems connected with the theory as well as the practice of the construction of ordnance. We are driven to the conclusion that the Ordnance Committee considered that such a course would have been dangerous to their self-respect; the deplorable ignorance which characterises all attempts at working out difficult questions by Committees would have been too glaringly exposed; it was much safer not to subject themselves to cross-examination.

If we are wrong, if the Committee have complete answers to the questions raised, it is open to them to convince the nation of the fact, because the sessions of the Institution of Civil Engineers will very soon commence, and some member of the Ordnance Committee should be deputed to read, not a popular lecture, but a serious paper that will demonstrate to a roomful of practical engineers that our guns have been constructed according to the rules which guide engineers in their ordinary work, and that yet they have failed. We have small hopes that the challenge will be accepted.

\section{THE MATHEMATICAL AND PHYSICAL SCIENCES}

Histoire des Sciences Mathématiques et Physiques. Par M. Maximilien Marie. Tomes I.-IX. (Paris: GauthierVillars, I883-86.)

MI. MARIE'S great work advances rapidly towards I. completion. The first three volumes appeared in 1883 ; the concluding three are in the press; we have now before us nine volumes, bringing down the narrative from the time of Thales to the time of Laplace. The undertaking is a vast one; and we are not surprised to hear that it has cost forty years of preparation. The learned world is to be congratulated that it has fallen into such able hands. M. Marie combines, in a rare degree, scicntific with literary qualifications. A certain grace and poignancy of style set off his wide erudition and practical acquaintance with methods of teaching. He can be vivacious even over processes of integration. The accumulated mass of his materials nowhere hinders the lightness of his tread. Keen touches of sarcasm enliven his most abstruse expositions, and agreeably remind bis readers that a sense of humour may subsist concurrently with a thorough mastery of the higher analysis.

He has accordingly produced a book which, with these merits and some corresponding defects, only a Frenchman could have written-one eminently interesting and original, at once lively and profound, instructive throughout if occasionally one-sided, frankly displaying the prepossessions of its author, and not unfrequently-as we shall presently show his heedlessness of historical and biographical accuracy. Its characteristic merit consists in the lucid interpretations contained in it of the older methods of mathematical research. The works of ancient and mediæval geometers are analysed, not barely in the view of exhibiting the results attained by them, but with the further purpose, most completely realised, of rendering their various artifices and modes of working intelligible to the least skilled in the archæology of mathematics. M. Marie's is indeed in no sense a book for beginners. It presupposes a considerable acquaintance with the most recent developments of analysis. The reader thus provided may, however, follow with ease and pleasure the steps by which earlier inquirers advanced; he may enter into their conceptions, place himself at their precise point of view, and while marvelling at the ingenuity which carried them so far, study the limitations of thought which hindered them from proceeding any farther. $\mathrm{He}$ may learn how the singular deficiency in the idea of abstract number which hampered the workings of such luminous and powerful minds as those of Archimedes, Apollonius, and Euclid, was supplied from the far East; how Hindu algebra and arithmetic formed the complement of Greek geometry; how both were transmitted through Arabic channels to Italy, and together constituted the starting-point of modern discoveries. Nor is it less curious to watch the gradual emergence of ideas big with the progress of the future, such as those of negative and imaginary, or infinitely small quantities; how they presented themselves with hesitation, and were at first shunned and distrusted; how they grew bolder and insisted on recognition; how their tent ative and partial treatment became widened and generalised until they finally developed the whole extent of their capabilities.

It is well known that Archimedes gave the first approximation to the value of $\pi$; but the occasion and significance of the step are often lost sight of. It marked, with the almost simultaneous attempt of Aristarchus of Samos to measure the relative distances from the earth of the sun and moon, the introduction of numerical calculation into theoretical researches (Marie, t. i. p. 59). The novel effort was prompted, in each case, by the interest of a special problem. Archimedes, naîvely enough, sought to prove that the idea of infinity had its root in enumerative impotence, and could be abolished by expanding the resources of arithmetic. He exemplified his contention by computing the number of grains of sand contained in a sphere with the interval from earth to sun for its radius. But a preliminary valuation of the ratio between the circumference of a circle and its diameter was indispensable; and the tract on the "Dimension of the Circle" was accordingly, in M. Marie's plausible view, written as a kind of preface to the "Arenarius." Incidentally to the calculations in the latter treatise, he perfected the Greek system of numeration, and foreshadowed the principle of logarithms.

M. Marie has ventured a kind of restoration of the "algebra" of Archimedes (t. i. p. 262). His remarks on this disputed subject are of great interest. He holds it impossible that his inventions should have been reached by the arduous path of his demonstrations; and ascribes to him, accordingly, the possession of a compendious method of reasoning founded on the transformation of 